\title{
Effect of haemodialysis on intraocular pressure
}

\begin{abstract}
Aims To study the effect of haemodialysis on intraocular pressure (IOP) of patients at the University Malaya Medical Centre, Kuala Lumpur, and the influence of anterior chamber angles, surgery, and diabetes on the change in IOP after haemodialysis.

Methods Prospective, single centre study on patients undergoing haemodialysis with a sample size of 98 eyes (49 patients). Ocular examination was performed before haemodialysis. Pre- and post-haemodialysis IOP measurements were taken. Plasma osmolarity changes and volume of fluid removed were noted. Patients on antiglaucoma treatment or who have had earlier laser or surgical procedures for it were excluded. Student's $t$-test and Pearson's coefficient test were used to determine the statistical significance.

Results Plasma osmolarity decreased significantly $(-11.6 \pm 10.0 \mathrm{mOsm} / 1, P<0.001)$. In eyes with occludable angles (8\% of cases), IOP decreased significantly $(-3.63 \pm$

$1.92 \mathrm{mmHg}, P<0.001)$. In non-occludable angle eyes (92\% of cases), no significant changes $(P>0.05)$ in all subgroups of non-operated/operated and diabetic/ non-diabetic eyes were seen.

Conclusions Haemodialysis does not cause significant changes in IOP in non-glaucomatous and non-occludable angle eyes.

Eye (2010) 24, 70-73; doi:10.1038/eye.2009.33;

published online 20 February 2009
\end{abstract}

Department of Ophthalmology, University Malaya Medical Centre, Kuala Lumpur, Malaysia

Correspondence:

A Samsudin,

Department of

Ophthalmology,

University Malaya Medical

Centre,

Lembah Pantai,

Kuala Lumpur,

Kuala Lumpur 59100,

Malaysia

Tel: + 0060178890999 ;

Fax: + 0060379494635 .

E-mail: a_samsudin@

hotmail.com

Received: 2 April 2008 Accepted in revised form: 24 January 2009

Published online: 20

February 2009
Keywords: haemodialysis; intraocular pressure; glaucoma

\section{Introduction}

Haemodialysis is an important and by far the commonest treatment for end stage renal failure (ESRF). In the 14th Report of the Malaysian Dialysis and Transplant Registry 2006, approximately 13600 out of 15000 patients
A Samsudin, Z Mimiwati, T Soong, MS Ahmad Fauzi and K Zabri
(91\%) with ESRF were undergoing haemodialysis ${ }^{1}$ (the number being more than 200000 patients in the United States in 1995) ${ }^{2}$.

Despite technical advances, haemodialysis is still far from ideal. Patients are exposed to potential complications, such as hypotension, muscle cramps, arrhythmias, bleeding disorders, hypoxia, and anaphylactic reactions. ${ }^{3}$ Ocular complications include reduced corneal endothelium cell density, ${ }^{4}$ ischaemic optic neuropathy, ${ }^{5}$ occipital lobe blindness, ${ }^{6}$ and endogenous endophthalmitis. ${ }^{7}$ Changes in intraocular pressure (IOP) during or after haemodialysis have also been widely reported in the literature. However, various studies have shown different and conflicting findings; many indicate that it may increase ${ }^{8-12}$ some indicate that it does not change, ${ }^{13,14}$ and some indicate that it even decreases. ${ }^{15,16}$

Levy et $a l^{17}$ performed a systematic review in 2005, and concluded that the influence of haemodialysis on IOP was still unclear. They suggested that further studies need to be performed. An extensive literature search has shown that until now, there have not been any published studies of this kind on the Malaysian population.

\section{Materials and methods}

\section{Study design}

This is a prospective, single centre study on patients undergoing haemodialysis at the University Malaya Medical Centre, Kuala Lumpur. Data collection was performed in December 2007.

\section{Procedure}

All patients registered for outpatient haemodialysis at the centre were invited to participate. Informed consent was taken from all participants. After taking a clinical history, ocular examination, including Snellen visual 
acuity, slit-lamp fundoscopy, applanation tonometry, and gonioscopy, was performed on both eyes. IOP

measurements were taken within $30 \mathrm{~min}$ before and after haemodialysis. The volume of fluid removed was recorded. Pre- and post-haemodialysis blood samples were collected for osmolarity analysis by freezing-point depression.

IOP was measured (average of two readings) with the patient sitting upright at the slit-lamp microscope, using the same calibrated Goldmann applanation tonometer

(Haag-Streit, Switzerland) for the whole period of study. To eliminate the intraobserver bias, one investigator (AS) performed all the measurements. Intradialysis IOP measurements were not recorded. Many studies have shown that IOP changes follow a linear trend with maximal changes occurring at the end of haemodialysis. ${ }^{9,10,15}$

Non-indentation gonioscopy with a Sussman gonioscope (Ocular Instruments, USA) was performed after taking the initial IOP measurement. To eliminate the intraobserver bias, the same investigator (AS) performed all the observations. For this study, the term 'occludable angle' was used when the posterior pigmented trabecular meshwork was not visible for $270^{\circ}$ of the angle circumference. This arbitrary definition has been used in earlier epidemiological studies to divide subjects into categories of primary open angle glaucoma (POAG) and primary angle closure glaucoma (PACG). ${ }^{18}$

Patients had uniform $4 \mathrm{~h}$, high-flux haemodialysis with total body heparinisation. These sessions started between 0600-0800 hours in the morning. Hollow-fibre cellulose acetate dialysers (Asaki Kasei, Japan) were used. Blood pump speed was between $180-200 \mathrm{ml} / \mathrm{min}$. Dialysate flow rate was $500 \mathrm{ml} / \mathrm{min}$. The dialysate contents were as follows: $\mathrm{Na}^{+} 140 \mathrm{mEq} / 1, \mathrm{~K}^{+} 2 \mathrm{mEq} / 1, \mathrm{Ca}^{2+} 2.5 \mathrm{mEq} / 1$, $\mathrm{Mg}^{2+} 1 \mathrm{mEq} / 1, \mathrm{Cl}^{-} 106.5 \mathrm{mEq} / 1$, and glucose $1 \mathrm{~g} / 1$.

\section{Exclusions}

Patients on antiglaucoma treatment or who have had earlier laser or surgical procedures for it $(n=1)$, or physically unable to be examined at the slit-lamp microscope $(n=2)$ were excluded. Glaucoma patients were those with at least two of these changes - typical glaucomatous visual field defects/typical glaucomatous optic disc features/raised IOP.

\section{Sample size calculation}

Before the study, an estimate of the sample size needed was derived using Win Episcope 2.0 (http://www.clive.ed.ac.uk/winepiscope) software. On the basis of the data derived from the study by Tokuyama et al $^{15}$ (means: 11.9 and 13.6, SD: 2.7, level of confidence: $95 \%$, power: $80 \%$ ), the minimum sample size needed was 84 eyes.

\section{Statistical analysis}

The mean \pm SD of each parameter for the whole group was calculated. These values were also separately determined in different groups. The significance of the change in IOP after haemodialysis was determined by the Student's $t$-test (paired samples). The Pearson coefficient test was used to determine the correlation between changes in IOP and that of plasma osmolarity, and the volume of fluid removed. A level of $<0.05$ was accepted as statistically significant.

\section{Ethical approval}

Ethical approval was obtained from the Medical Ethics Committee of the University Malaya Medical Centre before the start of the study. We certify that all applicable institutional and governmental regulations concerning the ethical use of human volunteers were followed during this research.

\section{Results}

This study included 98 eyes from 49 patients ( 25 men and 24 women, mean age: $54.4 \pm 12.5$ years, range: $20-84$ years) with ESRF. All patients had been undergoing regular maintenance haemodialysis for $4 \mathrm{~h}$ three times weekly for 1-192 months (mean duration: $40.7 \pm 41.1$ months).

Of the ocular disorders found, 16 eyes had proliferative diabetic retinopathy (PDR), 14 eyes had non-PDR (NPDR), 3 eyes had earlier pars plana vitrectomies (PPVs), 16 eyes were pseudophakic, and 13 eyes had cataracts. One eye had a central retinal vein occlusion (CRVO) previously. There were no eyes with angle neovascularisation or pseudoexfoliation.

During haemodialysis, none of the patients had symptoms or signs of acute raised IOP, such as blurring of vision, eye pain, headache, or corneal oedema.

Plasma osmolarity was decreased by $-11.6 \pm 10.0 \mathrm{mOsm} / 1(P<0.001)$. The volume of fluid removed was $3.0 \pm 0.81(P<0.001)$.

There were 90 eyes in the non-occludable angle group and 8 eyes in the occludable angle group. IOP changes were not significant in the non-occludable angle group, but significant in the occludable angle group (Table 1).

From the non-occludable angle group, we subanalysed the eyes by dividing them into non-operated $(n=72)$ and operated $(n=18)$, as well as diabetic $(n=46)$ and non-diabetic $(n=44)$ groups. Although the results were all non-significant, operated eyes averaged a small 
Table 1 IOP change after haemodialysis in the non-occludable and occludable angle groups

\begin{tabular}{llcccc}
\hline Angle & Mean \pm SD & P-value & \multicolumn{2}{c}{ 95\% confidence interval } \\
\cline { 3 - 6 } & & & Lower & Upper \\
\hline Non-occludable & IOP change $(\mathrm{mmHg})$ & $-0.37 \pm 3.36$ & 0.304 & -1.07 & 0.34 \\
Occludable & IOP change $(\mathrm{mmHg})$ & $-3.63 \pm 1.92$ & $<0.001$ & -5.23 & -2.02 \\
\hline
\end{tabular}

Table 2 IOP change after haemodialysis in the non-operated and operated eyes

\begin{tabular}{llcccc}
\hline Operated & Mean $\pm S D$ & P-value & \multicolumn{2}{c}{ 95\% confidence interval } \\
\cline { 3 - 6 } & & & Lower & Upper \\
\hline No & IOP change $(\mathrm{mmHg})$ & $-0.63 \pm 2.98$ & 0.079 & -1.32 & 0.07 \\
Yes & IOP change $(\mathrm{mmHg})$ & $0.67 \pm 4.56$ & 0.544 & -1.60 & 2.94 \\
\hline
\end{tabular}

Table 3 IOP change after haemodialysis in the diabetic and non-diabetic groups

\begin{tabular}{llcccc}
\hline$D M$ & Mean $\pm S D$ & P-value & \multicolumn{2}{c}{ 95\% confidence interval } \\
\cline { 3 - 6 } & & & Lower & Upper \\
\hline Diabetic & IOP change $(\mathrm{mmHg})$ & $-0.33 \pm 3.91$ & 0.574 & -1.49 & 0.83 \\
Non-diabetic & IOP change $(\mathrm{mmHg})$ & $-0.41 \pm 2.73$ & 0.326 & -1.24 & 0.42 \\
\hline
\end{tabular}

increase in IOP, whereas the non-operated, diabetic and non-diabetic eyes had small reductions in IOP (Tables 2 and 3 ). We could not differentiate between the effects of different procedures, for example, cataract surgery or vitrectomy on the eyes as the vitrectomised eyes also had earlier cataract surgery.

\section{Discussion}

In this study, in which $92 \%$ of patients did not have occludable angles, there was no increase in IOP following haemodialysis, despite the reduction in plasma osmolarity and fluid volume. It implies that acute reductions in plasma osmolarity or fluid shifts between body compartments are not enough to explain the changes as first reported by Sitprija et al ${ }^{12}$ in 1964. In that study, they suggested that the fall in plasma osmolarity (as solutes are removed during haemodialysis) results in the formation of a gradient between plasma and ocular tissue. This gradient encourages the movement of water from plasma into the tissue, namely the ciliary bodies, leading to the increased aqueous production and raised IOP.

We postulate that the use of newer and better haemodialysis techniques may be influential on our findings. Firstly, slower haemodialysis may have helped to prevent significant changes in IOP by reducing the rate of change in plasma osmolarity. The findings of significantly raised IOP by Sitprija et $a l^{12}$ were obtained when the rates were $-11 \mathrm{mOsm} / 1 / \mathrm{h}$, but Austin et al ${ }^{11}$ found no significant changes when the rate was $-7.7 \mathrm{mOsm} / 1 / \mathrm{h}$. In this study, the rate was $-2.9 \mathrm{mOsm} / \mathrm{l} / \mathrm{h}$. Additionally, although not strictly investigated in this study, all patients underwent high-flux haemodialysis. With this system, haemodialysis membranes allow larger molecules to pass, but not albumin. ${ }^{3}$ The resulting relative increase in plasma albumin concentration leads to higher colloid osmotic pressures, which draw water out of ocular tissue and into the plasma. As a result, a balance is formed, minimising the tendency for reduced plasma osmolarity to increase IOP.

There was a significant decrease in IOP in patients with occludable angles. This is in contrast to the findings of Tawara et al ${ }^{14}$ who reported that eyes with obstructed aqueous outflow pathways (including primary angle closure, peripheral anterior synechiae, angle neovascularisation, and ghost cell glaucoma) may develop IOP elevation due to a defective compensatory mechanism of aqueous humour drainage. We believe that our occludable angle eyes did not have any of the other features mentioned above. Additionally, the sample 
size for this particular group was small, and the decrease in IOP could be the result of a normal diurnal variation.

The state of the eye, whether operated or not, did not produce any significant changes. However, we are suspicious of the average increase in IOP in previously operated eyes, especially considering its small sample size. Yoon et $\mathrm{ll}^{19}$ reported that eyes which previously underwent vitrectomies were at risk of IOP elevation due to postoperative aqueous outflow compromise. In their sample of 36 vitrectomised eyes, $55.6 \%$ of them had an increase of $>4 \mathrm{mmHg}$ during haemodialysis. They suggested monitoring IOP during haemodialysis in these cases.

There were no significant changes in IOP during haemodialysis in both diabetic and non-diabetic eyes. It has been previously reported that high glucose levels in aqueous humour can increase fibronectin and extracellular matrix synthesis in the trabecular meshwork, again leading to aqueous outflow compromise. ${ }^{20}$ From our findings, we are unable to support that the effect is large enough to have a significant effect on IOP changes during haemodialysis.

This study did not take into account the duration after surgery or the control of diabetes. More accurate angle determination by ultrasound or optical coherence tomography (OCT) was also not performed. These could have assisted in the interpretation of changes.

\section{Conclusion}

Haemodialysis does not cause significant changes in IOP in non-glaucomatous and non-occludable angle eyes.

\section{Acknowledgements}

This study received a University Malaya Postgraduate Research Grant (ref PS291/2007B). This funding source did not have any other involvement or direct financial interest in this study.

\section{References}

1 Lim YN, Lim TO. 14th Report of the Malaysian Dialysis and Transplant Registry. National Renal Registry, Malaysian Society of Nephrology: Kuala Lumpur, 2006.

2 Arikan H, Tuglular S. The growing global burden of end stage renal disease (ESRD). Marmara Med J 2005; 18: 143-150.

3 Renal Replacement Therapy Clinical Practice Guidelines, 2nd edn. Nephrology Working Group, Ministry of Health: Malaysia, 2005.
4 Diaz-Couchoud P, Bordas FD, Garcia JRF, Camps EM, Carceller A. Corneal disease in patients with chronic renal insufficiency undergoing haemodialysis. Cornea 2001; 20: 695-702.

5 Basile C, Addabbo G, Montanaro A. Anterior ischaemic optic neuropathy and dialysis: role of hypotension and anaemia. J Nephrol 2001; 14: 420-423.

6 Al-Falki YH. Bilateral occipital infarcts in a haemodialysis patient. Am J Nephrol 2001; 21: 413-414.

7 Romero CF, Rai MK, Lowder CY, Adal KA. Endogenous endophthalmitis: case report and brief review. Am Fam Physician 1999; 60: 510-514.

8 Fleischhauer J, Keusch G, Abegg MH. Rise in intraocular pressure during haemodialysis in a patient with reduced outflow facility. Br J Ophthalmol 2007; 91: 1091-1093.

9 Masuda H, Shibuya Y, Ohira A. Markedly increased unilateral intraocular pressure during haemodialysis in a patient with ipsilateral exfoliative glaucoma. Am J Ophthalmol 2000; 129: 534-536.

10 Choong YF, Menage MJ. Symptomatic acute raised IOP following haemodialysis in a patient with end stage renal failure. Br J Ophthalmol 1998; 82: 1339a.

11 Austin JN, Klein M, Mishell J, Contiguglia SR, Levy J, Chan $\mathrm{L}$ et al. Intraocular pressures during high-flux haemodialysis. Ren Fail 1990; 12: 109-112.

12 Sitprija V, Holmes JH, Ellis PP. Intraocular pressure changes during artificial kidney therapy. Arch Ophthalmol 1964; 72: 626-631.

13 Costagliola C, Mastropasqua L. The influence of haemodialysis on intraocular pressure: III. Aqueous humour dynamics and tissue hydration. Ann Ophthalmol 1991; 23: 31-34.

14 Tawara A, Kobata H, Fujisawa K, Abe T, Ohnishi Y. Mechanism of intraocular pressure elevation during haemodialysis. Curr Eye Res 1998; 17: 339-347.

15 Tokuyama T, Ikeda T, Sato K. Effect of plasma colloid osmotic pressure on intraocular pressure during haemodialysis. Br J Ophthalmol 1998; 82: 751-753.

16 Doshiro A, Ban Y, Kobayashi L, Yoshida Y, Uchiyama H. Intraocular pressure change during haemodialysis. Am J Ophthalmol 2006; 142: 337-339.

17 Levy J, Tovbin D, Lifshitz T, Zlotnik M, Tessler Z. Intraocular pressure during haemodialysis: a review. Eye 2005; 19: 1249-1256.

18 Foster PJ, Aung T, Nolan WP, Machin D, Baasanhu J, Khaw PT et al. Defining 'occludable' angles in population surveys: drainage angle width, peripheral anterior synechiae, and glaucomatous optic neuropathy in East Asian people. Br J Ophthalmol 2004; 88: 486-490.

19 Yoon YH, Sohn JH, Lee SE, Lee YB, Kim JY, Kook MS. Increase in intraocular pressure during haemodialysis in eyes during early postvitrectomy period. Ophthalmic Surg Lasers 2000; 31: 467-473.

20 Li AF, Tane N, Roy S. Fibronectin overexpression inhibits trabecular meshwork cell monolayer permeability. Mol Vis 2004; 10: 750-757n. 